\title{
La Pluripotencialidad de la Especialidad de Medicina de Familia y Comunitaria
}

\section{Sr. Editor:}

En la VI Jornadas de Otoño de SCAMFYC se han abierto algunas "cajas de truenos". $Y$ es que todas las organizaciones acaban teniendo sus tabúes. Entre estos dogmas sacrosantos que algunos impíos nos hemos atrevido a poner en tela de juicio está el de la pluripotencialidad de la especialidad, con la petición de que nuestra Sociedad se inhiba en relación a la pretensión, en su mayoría de antiguos Médicos de Familia (de título que no de vocación), de crear una especialidad de urgencias.

Vaya por delante mi disculpa a quien pueda molestarse, y mi reconocimiento a la tarea que cada uno ha decido realizar en su vida profesional. Mi planteamiento no encierra reproches ni descrédito, es sólo un punto de vista estratégico de un Médico de Familia (MF) vocacional que no entiende otra ocupación para estos profesionales que la atención primaria. Así lo he entendido siempre, lo que no me ha impedido comprender que, en momentos en que las salidas profesionales para los residentes que terminaban eran complicadas, había que mantener abiertas otras opciones laborales.

Dentro de esta pluripotencialidad, la salida profesional en puertas de urgencia es una de las más atractivas para los residentes que terminan su formación. Tanta importancia ha adquirido esta dimensión del perfil del MF en España que el programa de formación ha ido adquiriendo un cierto sesgo en este sentido. Y así, las puertas de urgencia de los hospitales docentes están en manos de residentes de Medicina de Familia y Comunitaria. Este hecho se ha visto favorecido por la huida de los residentes de otras especialidades hacia la comodidad de sus guardias de planta, protegidos por jefes de servicio más preocupados de esa comodidad que de que adquieran una formación amplia (claro que para qué la van a necesitar en sus perfiles profesionales cada vez más superespecializados y desconectados de la realidad de los pacientes). Sin embargo, ha faltado una posición clara por nuestra parte frente a esta deriva inaceptable. $Y$ por si esto fuera poco, se han añadido nuevas "necesidades" formativas, que determinan que un R4 desaparezca dos días seguidos de su centro de salud por una guardia de emergencias, ya que incomprensiblemente no puede empezar la "espera de que ocurra algo", pongamos, a las 15 horas, en lugar de a las 9 .
No quiero con esto descargar responsabilidades sobre instancias lejanas, como la Comisión Nacional de la Especialidad, o más próximas, como las Unidades Docentes, ya que todos tenemos nuestra parte de culpa. De hecho, alguna culpa tendré en que alrededor de la mitad de mis residentes se hayan decantado por trabajar en urgencias, y mucha, desde luego, en haber consentido que algunos de mis residentes hayan empleado tiempo de su último año de residencia en realizar cursos superespecializados de urgencias, o que hayan trabajado como adjuntos de puertas de urgencia antes de terminar su formación.

La elección de una especialidad por parte de los graduados en medicina es un fenómeno multifactorial $^{1}$, y probablemente la deriva profesional posterior no lo sea menos, donde los azares de la vida pueden ser determinantes. Sin embargo, la realidad es tozuda y hay hechos incontrovertibles, como el escaso interés de los estudiantes de medicina por nuestra especialidad ${ }^{2}$. Desconozco la proporción de MF con formación MIR que trabajan en nuestra comunidad autónoma en atención primaria y puertas de urgencia (me parece que puede ser un trabajo interesante, y desde aquí animo a su realización), pero indudablemente entre los estudiantes que consideran la Medicina de Familia su primera opción laboral habrá "urgenciólogos" de vocación, lo que significa que el interés por la atención primaria entre los mismos es ínfimo.

Por esto nadie debe extrañarse cuando afirmo que para mi es motivo de frustración que una estudiante de medicina me diga que quiere hacer Medicina de Familia porque a ella lo que le gusta es la urgencia. Y mucho más motivo de frustración es que mis esfuerzos en formar MF no se aprovechen en nutrir nuestros centros de salud de más profesionales, y que de ese esfuerzo se aprovechen otros.

Seguro que, con el respaldo mayoritario de los socios, nuestra sociedad ha optado claramente por la defensa del perfil múltiple del MF, no en vano nuestro Presidente nacional es médico de una mutua. Esto, como señalaba antes, probablemente era obligado en tiempos de dificultades a la hora de encontrar salidas laborales. Pero hoy en día, en que la demanda supera a la oferta de profesionales, ya no puede ser un argumento. 
No nos engañemos, los MF somos los de "la atención continuada basada en la persona", y estamos en las antípodas de los que hacen "atención puntual basada en el síntoma". Quitémonos este lastre que nos está hundiendo cada vez más. Admitamos el planteamiento de los antiguos residentes, "MF" de título pero "urgenciólogos" de vocación, y facilitemos la creación de una especialidad de urgencias. Al menos, esto permitirá hacer una previsión de necesidades de especialistas en las convocatorias de MIR acordes a la realidad de cada ámbito asistencial.

\section{BIBLIOGRAFÍA}

1. Escobar F, López-Torres J. ¿Qué determina la elección de una Especialidad en Medicina? Rev Clin Med Fam. 2008; 2:216-25.

2. Escobar F, López-Torres J. Changes in the knowledge of and attitudes toward Family Medicine after completing a Primary Care course. Fam Med. 2010; 42: 35-40.

Francisco Escobar Rabadán Médico de Familia del Centro de Salud Universitario Zona IV de Albacete Profesor Asociado de la Facultad de Medicina de Albacete C/ Seminario, 4 - 02006 Albacete fjescobarr@sescam.jccm.es

\section{CAMBIO DE DIRECCIÓN}

Le rogamos nos avise con antelación en caso de cambio de dirección para no alterar el servicio de recepción de REVISTA CLIINICA DE MEDICINA DE FAMILIA.

Los cambios deben comunicarse en el teléfono 967507911 o a través del correo electrónico info@scamfyc.org

\section{SUSCRIPCIONES Y ATENCIÓN AL CLIENTE}

\section{SCAMFYC}

Dionisio Guardiola, 16, $4^{\circ} \mathrm{D}$

02003- Albacete

Teléfono y Fax: 967507911

Correo electrónico: info@scamfyc.org

Tarifa de suscripción anual

Profesionales 40,00 Euros (IVA incluido)

Instituciones 120,00 Euros (IVA incluido) 